\title{
A Proposal Concerning the Automatic Submerged Welding Procedures of Assemblies for Ship's Hull
}

\author{
By Toshio Yoshida, Member* \\ Wasuke Matsunaga, Member* \\ Kiyoshi Terai, Member* \\ Fumiyoshi Kanatani, Member*
}

\begin{abstract}
In carrying out the welding of the butt joints of the assemblies for ship's hull by means of the automatic submerged arc welding, there arises an important problem of preventing piercing with welding rod during welding process. Against the inaccurate processing of joint edge preparation, which is regarded to be the main cause of piercing, many researches have been conducted and counter-measures have been introduced. However, no satisfactory results have been obtained to date.

Therefore, the authors have devised a new edge form to replace the Unionmelt type edge preparation hitherto in use, thus attempting to solve this problem with its adoption. Known as Kawasaki's $Z$ type, this new form is the improvement of the edge preparation now in practice at the Chantiers de 1' Atlantique in France. In comparison with the edge preparations hitherto in use, this new edge form devised by the authors has greater allowable limit of root opening against piercing with welding rod. Furthermore, it is much easier to make edge preparation. These advantages have been proved by the experiments carried out by the authors.

Moreover, the authors have already applied this new edge form to actual constructions and carried out single pass submerged arc welding to thick steel plates up to the thickness of $60 \mathrm{~mm}$, thus obtaining successful results seen from the stand points of welding efficiency and joint performance.
\end{abstract}

\section{Introduction}

In carrying out the submerged arc automatic welding to the assemblies for ship's hull, there often arises the problem of piercing with welding rod during the first pass welding of the backing pass side. The cause is due to the large root opening on account of inaccuracy of edge preparation.

According to the Hand Book of the Unionmelt, the allowable root opening in butt joints should be less than $0.8 \mathrm{~mm}$. Moreover, the authors in their daily welding processing are experiencing piercing with welding rod when the root opening becomes larger than approximately $1 \mathrm{~mm}$. In spite of the fact that naval architects are exerting their utmost efforts in order to maintain the accuracy of edge preparation of the joint as it determines welding efficiency and joint performance in automatic welding process, it is very difficult at present to minimize without fail the error less than $0.4-0.8 \mathrm{~mm}$ as to the straightness of the joints of all steel plates when the single block is $12 \mathrm{~m}$ long in case edge preparations are to be made by flame planer.

As counter-measures, in addition to the increase of the accuracy of flame planer and prevention of distortion by the gas cutting heat, various shipyards in Europe and America are attempting to solve the problem by adopting the multi-electrodes automatic arc welding. Recently one of the authors during

原稿受付 昭和 35 年 1 月 8 日

* Kawasaki Dockyard Co., Ltd. Ship-building Dept 
his recent sojourn in France was interested in the fact that the Atlantique shipyard has been successful from the stand point of the prevention of piercing with welding rod in the submerged automatic arc welding joint through adoption of $Z$ type edge preparation as shown in Fig. 1 and that it has already obtained the approval of various ship classification societies.

Subsequently, the authors through experiments have found that the $Z$ type edge preparation of the Atlantique shipyard (simply known as $Z$ type edge preparation) is an excellent process for practical use.

At the same time the authors have come to know that it is not applicable to the plates, whose thickness exceed some $40 \mathrm{~mm}$. Accordingly, the authors tried to improve the form so that it can be applied to the plates of greater thickness. As a result, they have succeeded in devising the Kawasaki's: $\mathrm{Z}$ type edge preparation (simply known as $\mathrm{KZ}$ type), as shown in Fig. 2 and established the new process to be described below :

\section{Determination of $\mathrm{KZ}$ type edge preparation}

\section{(1) Difference between $\mathbf{Z}$ type and $\mathrm{KZ}$ type}

For carrying out automatic welding process to the ship's steel plates with the thickness up to 40 $\mathrm{mm}$, the $Z$ type edge preparation devised by the Chantiers de l'Atlantique has been approved by various ship classification societies and is protected by French patent. As shown in Fig. 1, the form of this edge preparation is such that the groove angle of edge preparation of both the backing and finishing passes is $60^{\circ}$ bilaterally.

In this case, since the rod aims at the bottom of groove the relative position of the rods for the finishing and backing passes becomes staggering in accordance with the ratio with the plate thickness. Although the idea of this edge preparation is excellent, according to the experiments carried out by the authors the thicker the plate, greater becomes the staggering of the shapes of penetrating nuggets. of the backing and finishing passes. Furthermore, when the plate thickness becomes greater than some $40 \mathrm{~mm}$, it often results in lack of penetration due to greater staggering. In order to prevent this, unreasonably large heat input is required.

In order to improve this $Z$ type edge preparation by removing its defect and retaining its merit against piercing with welding rod, the authors devised $\mathrm{KZ}$ type so that the penetrating form becomes. similar to that of Unionmelt's $\mathrm{X}$ type which has been in general use. Its form is shown in Fig. 2 .

Unlike $Z$ and $X$ types already described, whose groove shapes of both the right and left are symmetrical, KZ type edge preparation is not symmetrical. It is devised so that the beads of the backing and finishing passes meet without staggering, for which rod is placed in the middle of the breadth of shoulders of groove. In this case the arc comes mainly to the groove of the slope which is less steep. Naturally, the penetration forms will not become one-sided.

As for Kawasaki's Z-2 type, which is shown in Fig. 3, it is the combination of $\mathrm{KZ}$ and $Z$ types. This combination type is effective mainly in case of carrying out submerged arc welding of thin plates when one desires to use small heat input on the backing.pass side in order to prevent deep penetration and to use great heat input on the finishing pass side in order to obtain sufficiently great penetration.

\section{(2). Determination of the edge angle for $\mathrm{KZ}$ type edge preparation}

As shown in Fig. 1, in the case of $Z$ type the edge angles of both the right and left are $30^{\circ}$ each, making the total of $60^{\circ}$. As for $\mathrm{KZ}$ type, as shown in Fig. 4, the edge angle was determined by conducting welding tests by using specimens. For the tests, the edge angle on the root face was previously fixed at $30^{\circ}$, which is similar to that of $Z$ type. Moreover, it was based upon the principle of making the rods of both the finishing and backing passes line along one straight line.

As a result, the authors found that the most ideal edge angle for the slope less steep is $50^{\circ}$. In case of edge preparation with such angles, the position of the rod becomes in the middle of groove 

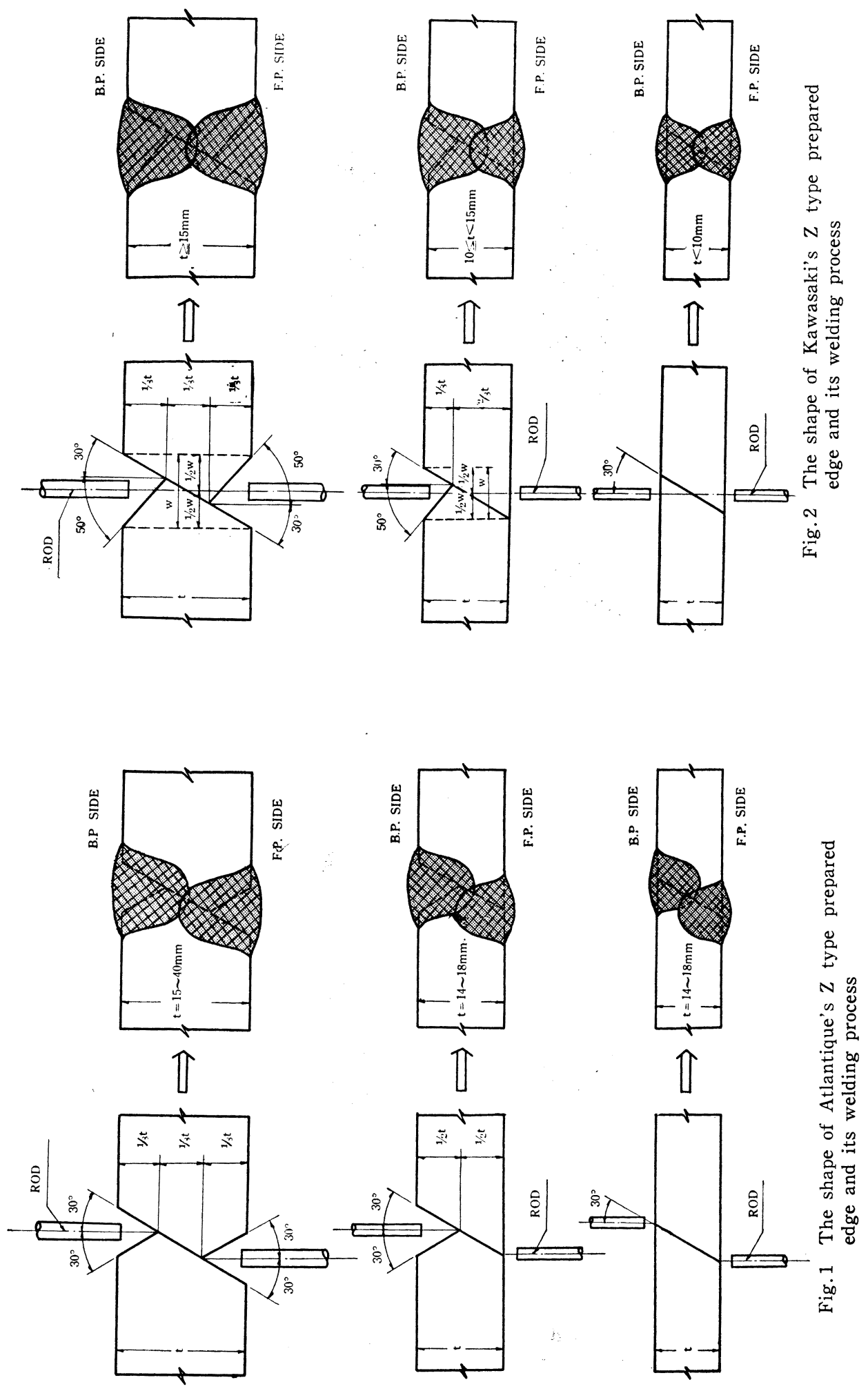


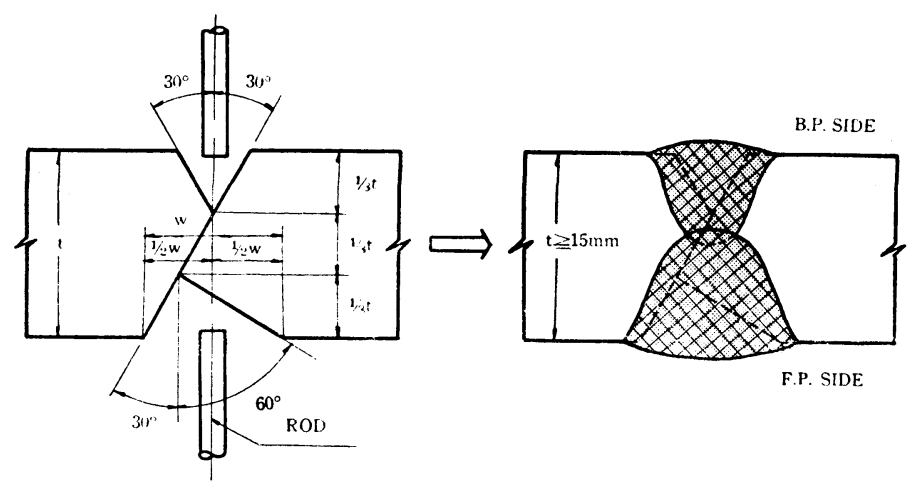

Fig. 3 The shape of Kawasaki's Z-2 type prepared edge and its welding process
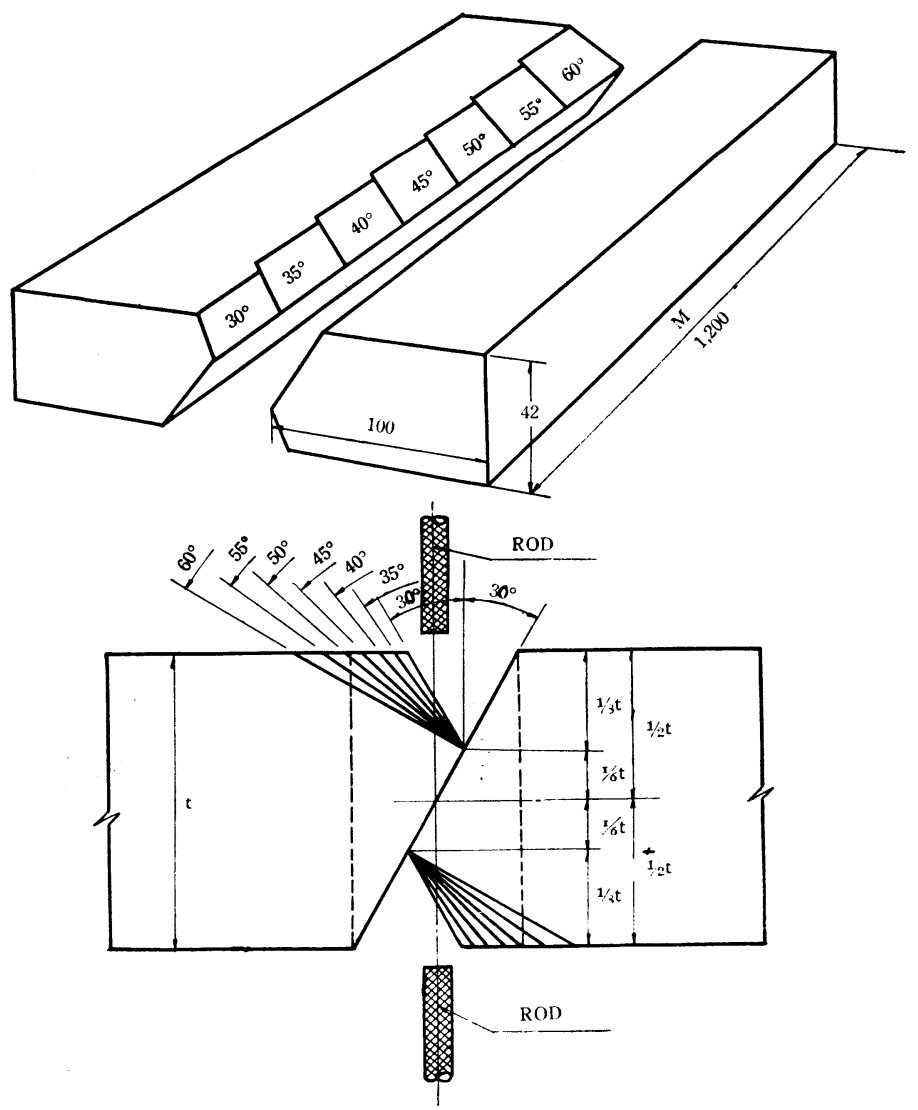

Fig. 4 Test specimen for deciding the edge angle for $\mathrm{KZ}$ type edge preparation

between both shoulders.

\section{(3) Determination of the depth of groove for $\mathrm{KZ}$ type edge preparation}

According to the standard welding conditions for single pass automatic welding explained in the Hand Book of the Unionmelt, the heat input on the backing pass side should be taken rather small in order to make penetration depth small and the heat input on the finishing pass side is made large in order to increase penetration depth to supplement it. Accordingly, the edge depth on the backing pass side is generally taken smaller than that on the finishing pass side.

However, in the application of this edge, when the thickness of the plate exceed some $40 \mathrm{~mm}$. the 
welding current on the finishing pass side surpasses 1,600 Amp. and so in actual practice in most cases current capacity of transformer for welding electric source becomes restricted. Moreover, the superficial appearance of the welding bead becomes far from being fine. Therefore, the authors are of the opinion that it is desirable to restrict the maximum current by equalizing the heat inputs of the backing pass side and finishing pass side as much as possible in carrying out the single pass welding of thick plates.

Accordingly, in making $\mathrm{KZ}$ edge preparation to be applied to the plates, whose thickness exceeds 15 $\mathrm{mm}$, the authors, due to the aforementioned reason, took the equal edge depths for both the finishing pass side and backing pass side. Furthermore, the authors thought it better, seen from the stand point of controlling edge preparing. Moreover, following that of $Z$ type edge preparation, the authors fixed the depth of the root face to $1 / 3$ of the thickness of the plate (cf Fig. 2). Moreover, in case of the application of the edge preparation for steel plates with the thickness less than $14 \mathrm{~mm}$, the depth of the root face was fixed to $2 / 3$ the plate thickness.

\section{Merits of $\mathrm{KZ}$ edge preparation}

\section{(1) Easy to prepare edge}

In comparison with that of the $\mathrm{X}$ type edge, the preparation of $\mathrm{KZ}$ type edge requires less gas cutt. ing process. In other words, in case of gas cutting by employing flame planer, three flame torches are required for preparing $\mathrm{X}$ type edge whereas only two torches are needed for making $\mathrm{KZ}$ type edge.

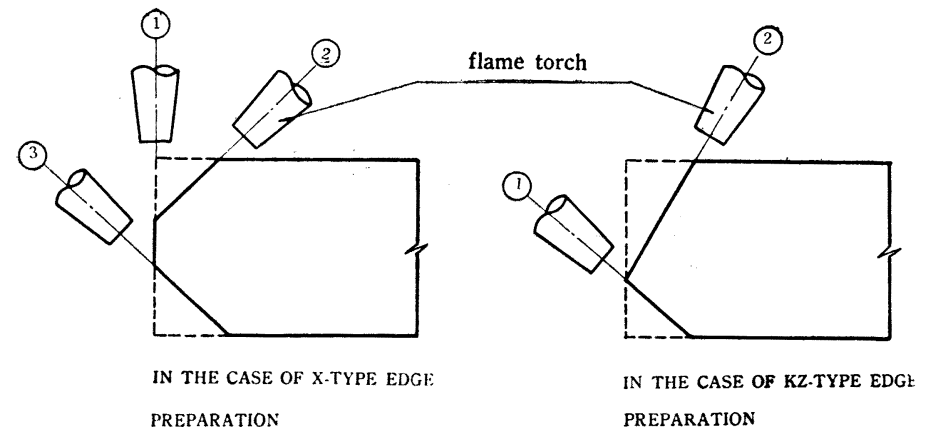

Fig. 5 Comparison of gas cutting processes for preparing edges

\section{(2) Merits of plate joint fitting}

In case the edge preparation is poor in accuracy and root opening exceeds allowable limit against piercing of weldingrod, the root opening can be made smaller by making locally staggering to the extent not perceivable by naked eyes(for instance, about $1 \mathrm{~mm}$ ) between the plates on both sides of the joint in making plate joint fitting, as shown in Fig. 6. By applying this operation, which will be described subsequently, to large actual constructions of great rigidity, namely $20 \mathrm{~mm}$ plate thickness and $2 \mathrm{~m}$ welding length, the authors

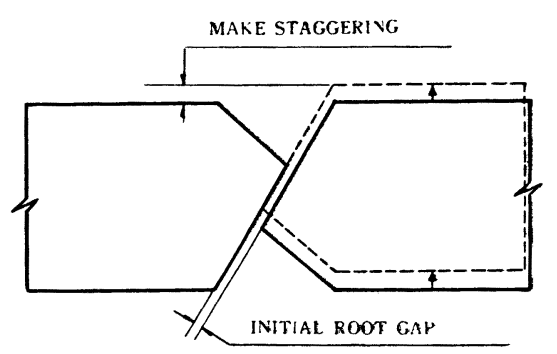

Fig. 6 Staggering method at the time of plate joint fitting

found it fairly effective. Such operation cannot be carried out in the case of $\mathrm{X}$ type edge preparation.

\section{(3) Superiority in allowable limit of root opening}

Making comparison between the shape of $\mathrm{X}$ type edge preparation and that of $\mathrm{KZ}$ type edge preparation, one will notice that although depths of root faces may be the same, the absolute length of the root face in the case of $\mathrm{KZ}$ type is longer than that of $\mathrm{X}$ type because it has a $30^{\circ}$ slope. And yet it does not hawe the root opening directly under the rod having the greatest arc force, contrary to the 
Table 1 Specimens for testing piercing with welding rod

\begin{tabular}{|c|c|c|c|c|}
\hline Plete & $\begin{array}{l}\text { Thickness } \\
\text { (mm) }\end{array}$ & KZ Type & Edge & X Type Edge \\
\hline & 12 & $10 \mathrm{p}$ & pieces & 10 pieces \\
\hline & 20 & 1 & $"$ & $1 "$ \\
\hline & 32 & 10 & " & $10 " \prime$ \\
\hline & 44 & 1 & " & 1 \\
\hline & 60 & 7 & $"$ & 7 \\
\hline
\end{tabular}

case of $\mathrm{X}$ type. Naturally, judging from the common sense, $\mathrm{KZ}$ type may be said to have greater allowable limit of root opening against piercing with welding rod than that of $\mathrm{X}$ type.

In order to prove this fact, the anthors carried out the tests of piercing with welding rod by using various test specimens, as shown in Table 1 during automatic weld-

ing process and have obtained the results, which are shown in Fig. 7.

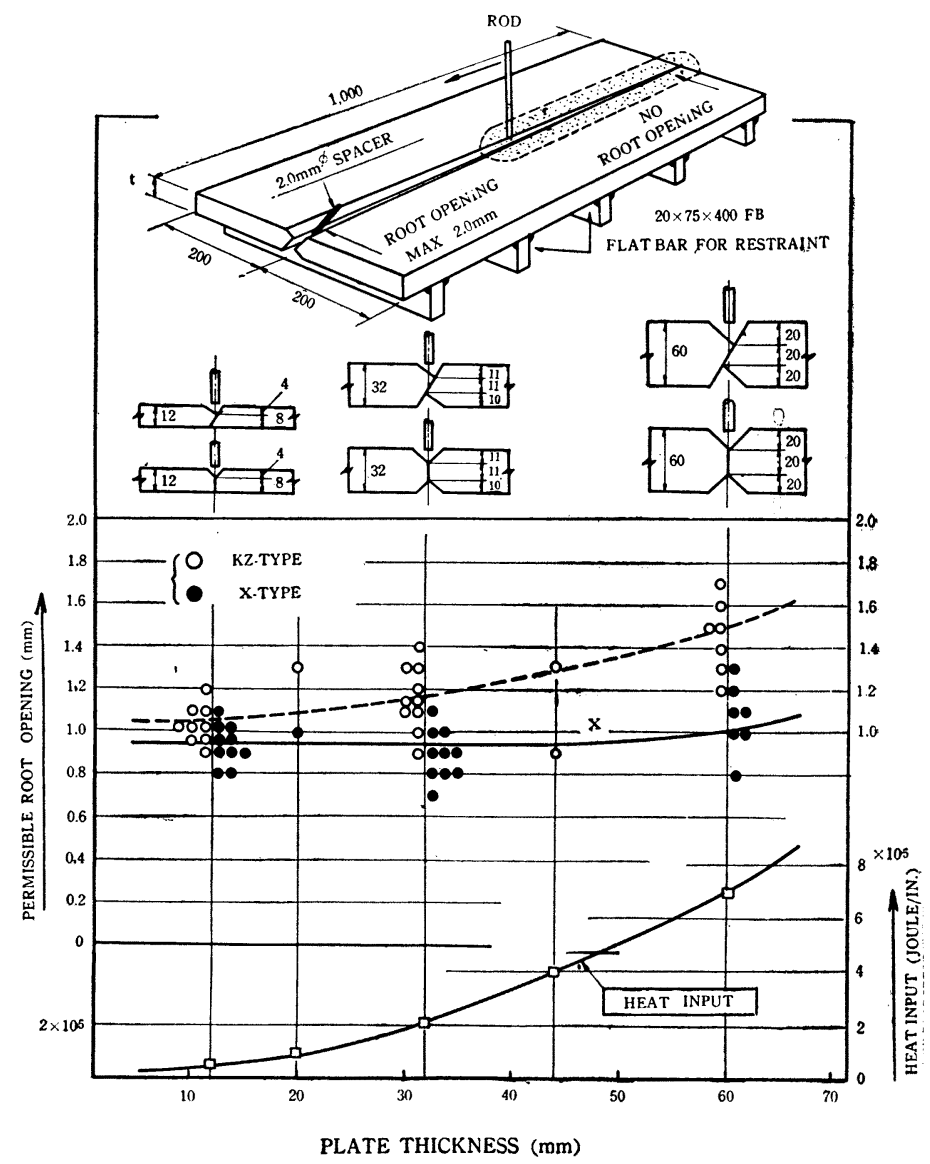

Fig.7 Results of comparative tests of allowable limit of root opening of $\mathrm{KZ}$ type and $\mathrm{X}$ type edge preparations against piercing with welding rod

As for the edge shapes, $\mathrm{KZ}$ type, as shown in Fig. 2, was used together with the one for $\mathrm{X}$ type whose root face depth was fixed at $1 / 3$ of the plate thickness in order to equalize the conditions of both. In making tack welding of the specimens, $2.0 \mathrm{~mm} \phi$ round bar was placed as spacer between the root of one end of the joint while the root of the other end was fixed so that the root opening becomes 0 . Thus, the root opening was varied continuously from 0 to $2.0 \mathrm{~mm}$. Next, in order to prevent the change of the root opening during operation, $20 \times 75 \times 400 \mathrm{~F}$. B. was welded transversely at the back of the specimen at right angle, moreover prior to the commencement of welding, the root openings were measured at the longitudinal intervals of approximately $100 \mathrm{~mm}$ and were recorded.

Then the values of the pre-welding openings at the spots where piercing with welding rod had occured were investigated and were plotted according to the steel plates of various thicknesses. Fig. 7 
shows allowable root openings thus investigated. Looking at Fig. 7, one will realize that the differences of allowable root openings of edge preparations of $\mathrm{X}$ and $\mathrm{KZ}$ types are clearly discernible when the plate thicknesses exceeds $30 \mathrm{~mm}$, although there is little difference between these types when the steel thick ness is around $12 \mathrm{~mm}$.

Greater the plate thickness, greater the difference. When the plate thickness is $60 \mathrm{~mm}$, the allowable root gap of $\mathrm{KZ}$ type is on the average some $0.5 \mathrm{~mm}$ greater than that of $\mathrm{X}$ type. The values of the allowable gap openings of various plate thicknesses, which are shown in Fig. 7, differ considerably in accordance with the welding condition, namely heat input, of each plate of different thicknesses, Therefore, the differences of the allowable root gap of these two different types can hardly be determined absolutely. However, judging from the general trend, at least it is clear that the KZ type edge preparation has greater allowable root gap against piercing with welding rod that of $\mathrm{X}$ type.

Even if such difference might be only $0.3 \mathrm{~mm}$, the adoption of $\mathrm{KZ}$ type edge preparations in practical welding operations would mean that the welding joints of the assemblies for ship's hull, which would be free from the risk of piercing with welding rod, would extend to extremely vast areas.

\section{(4) Symmetry of penetrating shape}

According to Kawasaki's $Z$ type edge preparation, as shown in Fig. 2, the welding rod of the finish ing pass side and that of the backing pass side are so fixed that the rods of both sides line along one straight line and so the right and left sides of the piercing shape become perfectly symmetrical. In this respect, it is quite same as the penetrating shape of Unionmelt's $X$ type edge preparation. On the other hand, in the case of that of Atlantique's $Z$ type the penetrating shape of the finishing pass side and that of the backing pass side becomes staggering, which becomes larger in ratio to the greater plate thickness. Designed to indicate the plate thickness allowable limit of $Z$ type edge preparation, Fig. 8 shows the comparison between the penetrating shape of $\mathrm{Z}$ type edge preparation and that of $\mathrm{KZ}$ type as tested by the macro-etched structure test of the welding joints of the two types.

In this test the plates with the thicknsses of $6,12,20,30,40,50$ and $60 \mathrm{~mm}$ were used. As for the edge shapes of $Z$ type and $\mathrm{KZ}$ type, those shown in Figs. 1 and 2 were tested. Studying Fig. 8, one will notice that in the case of $\mathrm{KZ}$ type edge preparation satisfactory joints are obtainable up to the $60 \mathrm{~mm}$ plate thickness whereas in the case of $Z$ type imperfect penetrating results at $40 \mathrm{~mm}$ plate thickness.

The following cause can be considered as to the smaller allowable limit of the plate thickness in the case of $Z$ type :

The shape of the penetrating nugget of the submerged automatic arc welding part does not become larger identically in ratio to the welding current but there is the tendency of it becoming deeper against its breadth and its bottom shape becoming sharper as the current becomes higher. Therefore, greater the plate thickness, severer the effect of this tendency from the stand point of the staggering. of the penetratings of the upper and the lower.

The value of $40 \mathrm{~mm}$ allowable limit of plate thickness in connection with $Z$ type edge preparation indicated in Fig. 8 is not an absolute value and it is conjectured that it will vary considerably according to heat input, root opening, diameter of welding rod, angle of inclination of welding rod, etc., in each plate thickness. The Atlantique shipyard, which is adopting this edge preparation in practise, is fixing the allowable limit of plate thickness at $40 \mathrm{~mm}$, which is reasonable, judging from the results shown in Fig. 8.

\section{Application of $\mathrm{KZ}$ type edge preparation on actual constructions}

As already explained above, the authors have ascertained through tests the superiority of Kawasaki's 


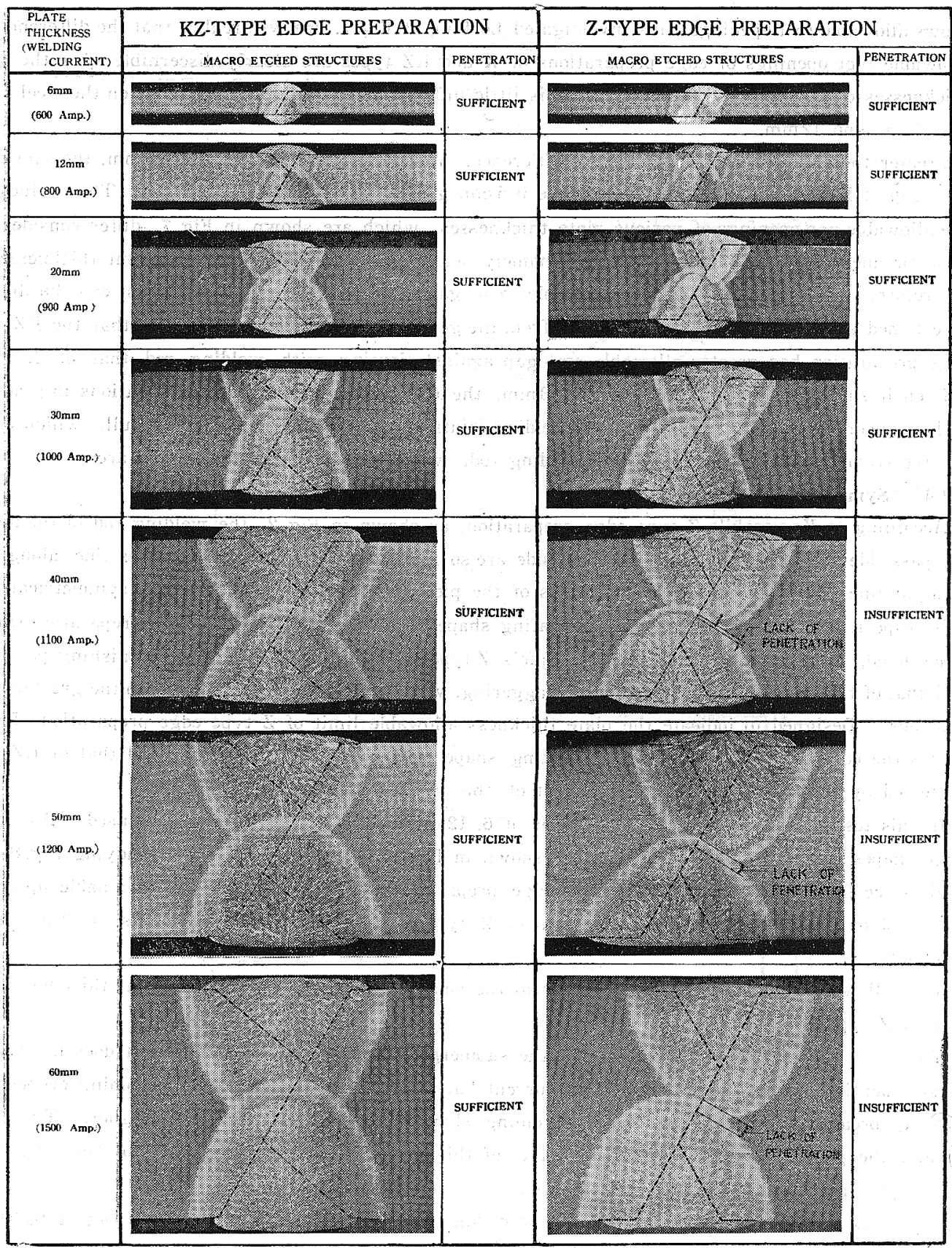

Fig.8 Comparison of the macro-etched structures of the welding joints of $\mathrm{KZ}$ type and $Z$ type edge preparations

$Z$ type edge preparation to those of Unionmelt's $\mathrm{X}$ type and Atlantique's $\mathrm{Z}$ type in connection with the single pass submerged arc welding. Next, the authors would like to explain briefly their experiences in the application of $\mathrm{KZ}$ type to actual constructions.

During of July-November, 1959 Kawasaki Dockyard manufactured blast furnace shell plates for the Chiba Iron Refinery of Kawasaki Steel Corporation and have succeeded in promoting production efficiency considerably and in turning out superior joints without cracks and other flaws through application of this new KZ type edge preparation and single pass automatic arc welding process in the work of 
joining steel plates of $32,40,50$ and $60 \mathrm{~mm}$ thicknesses prior to bending.

The edge shapes and welding conditions applied for the work are shown in Table. 2. In the case of the 50 and $60 \mathrm{~mm}$ thick. Plates in this Table, the edge angles used are different from those shown in Fig. 2, one side being $25^{\circ}$ and the other side $43^{\circ}$.

Table 2 Welding conditions applied to the joining work of the blast furnace shell plates

\begin{tabular}{|c|c|c|c|c|c|c|c|}
\hline $\begin{array}{c}\text { Plate } \\
\text { thickness } \\
(\mathrm{mm})\end{array}$ & Shape of edge preparation & Pass & $\begin{array}{l}\text { Welding } \\
\text { current } \\
\text { (amp.) }\end{array}$ & $\begin{array}{l}\text { arc } \\
\text { Voltage } \\
\text { (volt.) }\end{array}$ & $\begin{array}{l}\text { Welding } \\
\text { speed } \\
\text { (in } / \mathrm{min})\end{array}$ & $\begin{array}{l}\text { dia } \\
\text { of rod } \\
\text { (in } \varnothing \text { ) }\end{array}$ & red \& flux \\
\hline 32 & & $\begin{array}{l}1 \\
2\end{array}$ & $\begin{array}{l}1050 \\
1050\end{array}$ & $\begin{array}{l}35 \\
35\end{array}$ & $\begin{array}{l}12 \\
12\end{array}$ & $1 / 4$ & \multirow{4}{*}{$\begin{array}{l}\text { Oxweld } \\
\text { No } 36 \\
\text { rod } \\
\times \\
\text { Unionmelt } \\
\# 20 \\
\text { flux }\end{array}$} \\
\hline 40 & & $\begin{array}{l}1 \\
2\end{array}$ & $\begin{array}{l}1150 \\
1150\end{array}$ & $\begin{array}{l}36 \\
36\end{array}$ & $\begin{array}{l}9 \\
9\end{array}$ & $1 / 4$ & \\
\hline 50 & 20 & $\begin{array}{l}1 \\
2\end{array}$ & $\begin{array}{l}1300 \\
1300\end{array}$ & 36 & 7 & $3 / 6$ & \\
\hline 60 & & 2 & $\begin{array}{l}1550 \\
1550\end{array}$ & $\begin{array}{l}36 \\
36\end{array}$ & 5 & $5 / 6$ & \\
\hline
\end{tabular}

The reason is that there is the possibility of imperfect welding because deposited metal does not spread out sufficiently when the breadth of shoulders of the edge preparation becomes too large along with the

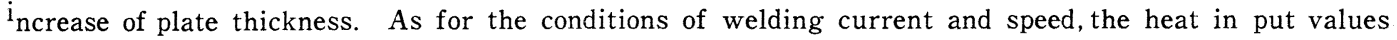
were taken slightly higher than those obtained by sufficiently tested preliminary tests in consideration of surety against imperfect penetrating nugget.

At the beginning, it was thought that the accuracy of the edge preparation of the joints for 50 and $60 \mathrm{~mm}$ thick plates would be a problem. Therefore, the authors measured the accuracy of the prepared edges of all shell plates tested and recorded the degree of accuracy. According to the results of this measurement, fairly excellent accuracy was obtained in regard to edge angles and depths. However, as to the straightness of edges of joints sufficiently satisfactory accuracy could not be obtained.

Fig. 9 indicates the results of the measurement of the straightness of the edges of joints of 69 sheets of $60 \mathrm{~mm}$ thick steel plates which have been tested. According to this, the probability of the maximum root opening becoming $0.5-1.0 \mathrm{~mm}$ in case of butting two steel plates is more than $50 \%$. But according to the measurement of root opening under tack weld condition in practice, there were several instances with $1.5 \mathrm{~mm}$ maximum. In these cases, aforementioned staggering method was applied in order to shorten the opening to $0.5 \mathrm{~mm}$ or so in carrying out welding.

Although the $\mathrm{X}$-ray test as to the soundness

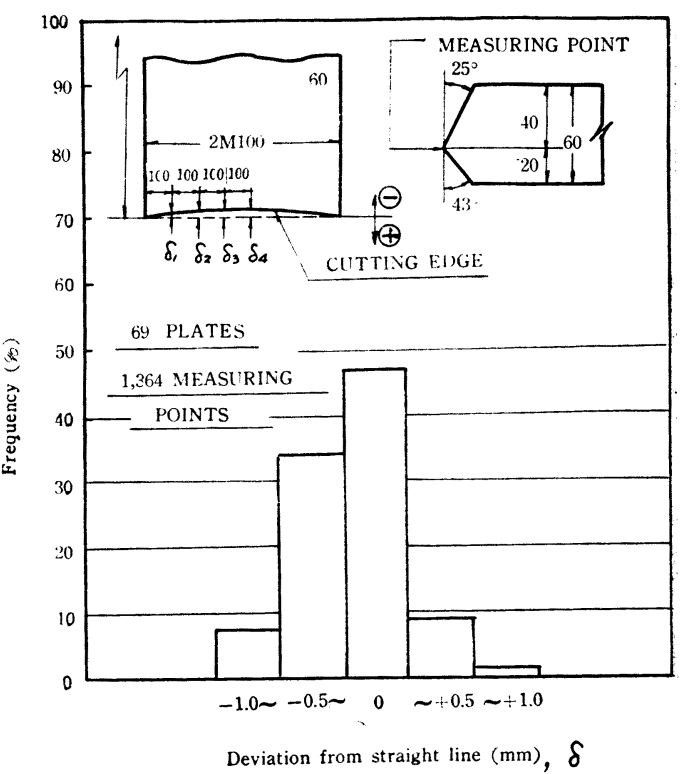

Fig. 9 Accuracy of processing $\mathrm{KZ}$ type edge preparations by flame planer 
of welded joints was not carried out due to the capacity limit of the $\mathrm{X}$-ray equipment, the penetrating condition was inspected by means of macro structure test by obtaining test specimen from the run-off -tab from each of the plates. By using the Unionmelt \#20 $(20 \times \mathrm{D})$ as flux, fairly beautiful bead waves could be obtained even if $1600 \mathrm{Amp}$. high current was used.

\section{Conclusion}

(1) The characteristics of Kawasaki's $Z$ type edge preparation, which is the improvement of Atlantique's $Z$ type, are that its right and left are not symmetrical and that the position of the welding rod of the backing pass side and that of the finishing pass side are in a straight line(cf. Figs. 1 and 2).

(2) The first advantage of Kawasaki's $Z$ type edge preparation is that the allowable limit of root opening against piercing with welding rod is greater. According to the results of tests, the allowable limit of root opening of this type is greater by some $0.2-0.5 \mathrm{~mm}$ than that of $\mathrm{X}$ type of the same root depth (cf. Fig. 7)

(3) The second advantage of Kawasaki's $Z$ type edge preparation is that unlike Atlantique's $Z$ type it has no limit in plate thickness. The results of tests show that in the case of Atlantique's $Z$ type welding becomes impossible due to imperfect penetration when the plate thickness exceeds approximately $40 \mathrm{~mm}$ (cf. Fig. 8)

(4) The third advantage of Kawasaki's $Z$ type edge preparation is that it requires only two processings in gas cutting process in preparing edge. Moreover, the root opening can be lessened to a certain extent by means of the staggering method during tack welding (cf. Figs. 5 and 6).

(5) The authors have succeded in applying Kawasaki's $Z$ type to actual constructions of plate thickness up to $60 \mathrm{~mm}$ and the superiority of this type has been proved in practise.

\section{Acknowledgement}

The authors exp ress herewith deep gratitude to Messrs. Moranton, Edouard and Vogelweith of Chantiers de I Atlantique and Mr. A. Audige of Chamber Syndicale des Constructeurs de Navires for their worthy instructions given in the knowledge of Atlantique's $Z$ type edge preparation, and to Professors Terazawa and Ôtani of Ôsaka University, Department of Technology and Professor Kihara of Tokyo University, Department of Technology for their invaluable guidance and instructions given in the compilation of this paper. 